\title{
MIDAS
}

Museus e estudos interdisciplinares

\section{Políticas culturais e museus: algumas perspectivas}

cultural policies and museums: some perspectives

Ana Carvalho, Clara Frayão Camacho e Raquel Henriques da Silva

\section{(2) OpenEdition}

Journals

\section{Edição electrónica}

URL: https://journals.openedition.org/midas/2984

DOI: $10.4000 /$ midas. 2984

ISSN: 2182-9543

\section{Editora:}

Alice Semedo, Paulo Simões Rodrigues, Pedro Casaleiro, Raquel Henriques da Silva, Ana Carvalho

\section{Refêrencia eletrónica}

Ana Carvalho, Clara Frayão Camacho e Raquel Henriques da Silva, «Políticas culturais e museus: algumas perspectivas», MIDAS [Online], 13 | 2021, posto online no dia 15 dezembro 2021, consultado no dia 07 março 2022. URL: http://journals.openedition.org/midas/2984 ; DOI: https://doi.org/ $10.4000 /$ midas.2984

Este documento foi criado de forma automática no dia 7 março 2022.

\section{cc) (1) (ㅇ)}

Midas is licensed under a Creative Commons Attribution-NonCommercial-ShareAlike 3.0 International License 


\title{
Políticas culturais e museus: algumas perspectivas
}

\author{
Cultural policies and museums: some perspectives
}

Ana Carvalho, Clara Frayão Camacho e Raquel Henriques da Silva

1 O desenvolvimento dos museus é, em grande medida, influenciado pelas políticas culturais de cada país. ${ }^{1}$ Por política cultural entendemos a definição e a promoção de um conjunto de valores e de acções na esfera da cultura, que num dado momento ou contexto procuram responder às necessidades e preocupações na sociedade onde se inscrevem, atendendo aos recursos disponíveis. O seu desenvolvimento é por isso mutável, variando conforme as mudanças políticas, económicas, sociais e culturais que se operam na sociedade, reflectindo em cada momento escolhas e aspectos que são mais valorizados em detrimento de outros.

2 O desenvolvimento e a implementação de políticas culturais são uma responsabilidade dos Estados, refletida na atuação de múltiplos actores na esfera pública e a vários níveis de governação: central, regional e local. No domínio das políticas culturais destaca-se igualmente a influência e o agenciamento de outros enquadramentos, actores, instrumentos e orientações (ex. cartas, convenções, recomendações, relatórios) a escalas supranacionais, nomeadamente ao nível da União Europeia, de forma mais direta ou indireta (Höglund 2012), ou a uma escala mais global (ex. UNESCO ou OCDE).

3 A formulação de políticas culturais varia também em função do contexto histórico, cultural, social, económico, filosófico ou ideológico em que se produzem, que difere de país para país. Por essa razão também não é raro identificarem-se diferentes abordagens na forma como se definem, desenvolvem e se implementam políticas culturais, cujos aspectos comuns e diferenciadores são também objecto de comparabilidade (Anico 2009; Poirrier 2011; Lill e Arne 2012).

4 O enquadramento em que se definem políticas culturais é ainda condicionado por eventos ou fenómenos de escala mais global, que podem introduzir mudanças significativas e aportar impactos para as políticas culturais nacionais. Esse é o caso da globalização, mas também de crises, como a pandemia Covid-19 - uma crise de saúde 
pública que tem afectado todos os sectores da sociedade, incluindo os museus, tal como evidenciam os relatórios produzidos nos últimos anos (Ibermuseus 2020 e 2021; UNESCO 2020; ICOM 2020; NEMO 2021). Mas poderiam ainda ser referidas outras crises, como as de origem económica (ex. crise financeira internacional pós-2008; ou a crise da dívida soberana portuguesa a partir de 2011), política (ex. movimentos de contestação social antirracismo, entre outros), social (ex. movimentos migratórios e crise de refugiados) ou ambiental (ex. Antropoceno), entre outras.

5 As políticas culturais são determinantes para potenciar o lugar dos museus na sociedade, o seu alcance e relevância. Enquanto beneficiários das políticas culturais de cada país, os museus são influenciados pelas orientações dessas políticas, dos seus objectivos e estratégias, das prioridades, dos mecanismos e instrumentos de gestão, do controle e regulação implementados, assim como dos recursos alocados (financeiros e humanos). Aliás, o papel que as políticas públicas podem ter na recuperação do sector dos museus (e do sector cultural de forma mais abrangente) no período pós-pandemia, tem sido muito evidenciado nos relatórios já referidos como factor determinante para reactivar o sector e corrigir as assimetrias identificadas.

6 A reorganização de museus, seja por via da criação de novos museus, encerramento/ extinção, fusão ou investimento na sua expansão ou requalificação, a distribuição de recursos, incluindo o seu aumento e/ou redução, a diversificação de fontes de financiamento, a descentralização, a desconcentração, a criação de redes, a credenciação de museus, a regionalização, a privatização de museus ou de parte da sua actividade, a diversificação de modelos de gestão, e a produção e regulação legislativa são alguns dos aspectos geralmente explorados e desenvolvidos sob a alçada das políticas públicas. Também inerentes às políticas públicas são as formas como se estruturam as instituições de enquadramento, compreendendo a (re)organização de organismos do Estado, assim como as suas divisões orgânicas ou fusões.

7 As políticas culturais têm implícitos entendimentos sobre nação, identidade(s), diversidade cultural e acesso. Sobre a ideia de acesso, são vários os países, como é o caso de Portugal, em que a Constituição da República, aprovada em 1976, afirma o direito de todos à cultura (artigo $73^{\circ}$ ). Além disso, as políticas culturais têm por base abordagens assentes na democratização da cultura e/ou na democracia cultural, que baseando-se em paradigmas distintos (Lopes 2009), por vezes coexistindo (Négrier 2020; Vale 2021), evocam perceções sobre como deve ser entendida a cultura e as condições em que se promove o seu acesso, levantando várias interrogações: que cultura(s)? Com quem, para quem e como?

8 Também se evidencia o papel da participação, que tem sido objecto de interesse crescente na concretização de políticas públicas (Négrier 2020), enquanto mecanismo que pode desencadear novas formas de envolvimento com vista à melhoria da acção pública, constituindo «a participação como 'desafio de' e objectivo para a democratização» (Carvalho e Falanga 2016, 29).

$9 \mathrm{Na}$ contemporaneidade espera-se, cada vez mais, que os museus desempenhem múltiplas funções e que contribuam para a concretização de objectivos de políticas que não são estritamente do domínio da cultura (Legget 2017a; Camacho 2021), nomeadamente nas áreas da educação, da ciência, da saúde e do bem-estar, do combate à exclusão social, da coesão territorial, do desenvolvimento turístico, da promoção do desenvolvimento sustentável, da igualdade e da diversidade, da criatividade, da inovação e do empreendedorismo, entre outras. Neste contexto sobressai a ideia de 
abordagens integradas, intersectoriais e de políticas de convergência e de cooperação que atravessam as várias áreas governamentais numa visão menos compartimentalizada da cultura e das políticas públicas e de distribuição de responsabilidades. Por outro lado, no domínio do próprio sector cultural também se observa, não raras vezes, uma tendência para a separação das várias áreas (artes, museus, património, arquivos, bibliotecas), fazendo corresponder a cada uma organismos específicos de actuação, mas nem sempre comunicantes entre si.

10 Vivemos um tempo de maior escrutínio público e de maior demanda quanto à necessidade de um planeamento mais estratégico, em termos de pensamento e de aç̧ão, e de uma maior racionalização ou optimização de meios, aspectos que recaem sob a responsabilidade das políticas públicas, mas que também emanam do próprio sector museológico. Podem ser referidas, a título exemplificativo, algumas iniciativas no contexto governamental que ilustram estas preocupações e apresentam propostas de médio prazo. É o caso do mais recente plano estratégico do Arts Council do Reino Unido (2019), a política museológica do Ministério da Educação e da Cultura da Finlândia (Mattila 2018), o Livro Branco da política cultural norueguesa (Norwegian Ministry of Culture 2019) e a Missão Museus Século 21, promovida pelo Ministério da Cultura de França (Eidelman 2017). Em Portugal destaca-se o relatório Museus no Futuro (Camacho 2021), um conjunto de recomendações e propostas, que resulta do Grupo de Projecto com o mesmo nome, e que corresponde a uma iniciativa governamental inédita nas políticas públicas do património e dos museus no país.

11 Não obstante, se, por um lado, se verifica a necessidade de um pensamento estratégico num tempo mais dilatado, com frequência o sector dos museus confronta-se com a alternância dos ciclos políticos nos governos e a consequente oscilação e mudança de prioridades e de investimento, que daí resulta para o mundo dos museus, assim como para o sector cultural de forma mais alargada.

12 Merece ainda referência o envolvimento dos profissionais de museus na definição de políticas públicas para o sector. Entendidos como beneficiários dessas políticas, os museus ou os seus representantes são, por vezes, consultados, mas com menos frequência são tidos como actores mais activos na elaboração de políticas públicas (Hushion 2006b, 5). Poderá uma política ser bem-sucedida se não se dinamizar também de baixo para cima, com abertura e flexibilidade, envolvendo os museus e os seus profissionais, visando uma responsabilidade partilhada em torno de um horizonte comum? Neste sentido, os museus podem e devem ser laboratórios permanentes da elaboração e re-elaboração das políticas públicas.

13 A reflexão sobre o papel e o impacto das políticas públicas, seja de forma mais específica no sector museológico, seja no sector cultural de forma mais global, não é um tema novo e tem sido objecto de análise, a partir de diferentes ângulos (e.g. Hushion 2006b; Lang, Reeve, e Woollard 2006; Gilabert González 2011; Bonet e Négrier 2011; Lill e Arne 2012; Camacho 2015; Poulot 2016; Garcia et al. 2016; Legget 2017b, entre outros). Todavia, o tema continua a suscitar novos olhares, investigação e perspectivas em função das mudanças diversas e multifacetadas que se têm operado nas últimas décadas e em especial nos últimos anos, não ignorando o impacto de diferentes e subsequentes crises no panorama museológico.

14 Este é o contexto reflexivo de partida que está na génese da chamada de propostas para este número temático. Com este número pretendemos contribuir para uma reflexão crítica sobre o papel das políticas culturais dirigidas a museus, recolhendo algumas 
perspectivas e experiências. O dossier está longe de ter esgotado todas as dimensões pensadas na chamada de propostas esboçada inicialmente, mas é um ponto de partida para se continuar a reflectir sobre este campo de análise, que no contexto português em particular continua a suscitar investigação e o aprofundamento dos temas.

O dossier abre com o artigo «Políticas Culturais de Museus em Portugal e Processos de Reflexão Estratégica Participada», de José Soares Neves. O autor parte do amplo espectro das políticas públicas da cultura e da identificação de dois ciclos por vários autores: o primeiro, de crescimento até 2008 e o segundo, de crise, sustentando a emergência de um novo ciclo de crescimento, a partir de 2019. Com esta hipótese como pano de fundo, revisita, numa abordagem comparativa, duas iniciativas de reflexão no campo dos museus - a Estrutura de Projecto da Rede Portuguesa de Museus (2000) e o Grupo de Projecto Museus no Futuro (2019). José Soares Neves conclui que o pensamento estratégico participado e o financiamento são algumas das bases de sustentação das políticas públicas centrais de museus neste novo ciclo. Embora estas políticas sejam na actualidade mais direcionadas para os museus, palácios e monumentos de tutela da cultura, não esquecem a acção da Rede Portuguesa de Museus (RPM), através de propostas para a sua revitalização. $O$ autor reflecte ainda sobre duas grandes orientações das políticas culturais - a democracia cultural, associada à RPM, e a democratização da cultura, no qual se filia predominantemente o Grupo de Projecto Museus no Futuro - e sobre o paradigma participativo nas políticas públicas, presente em ambas.

o dossier prossegue com «Reflexão sobre Políticas Públicas e Gestão de Acervos em Instituições de Memória em Portugal». As autoras, Graça Filipe, Conceição Serôdio Calvão Borges e Ana Margarida Dias da Silva reflectem sobre políticas de incorporação e desincorporação em instituições de memória, referindo-se aos arquivos, bibliotecas e museus, através de uma análise integrada e comparativa. Concluem que a desincorporação, entendida aqui como o processo inverso à incorporação, deve fazer parte de uma política sustentada de colecções. No entanto, alertam para a ausência de desenvolvimento do tema, seja no plano estratégico das instituições de memória, seja ao nível do desenvolvimento teórico. Analisando a produção legislativa portuguesa sobre o tema da incorporação e desincorporação de acervos, as autoras observam que a legislação em vigor não é limitativa de acção política, mas advertem para a necessidade de maior definição estratégica, assim como para a importância de consolidar e reforçar meios.

17 Ainda sobre acervos, mas sob um outro prisma, segue-se o artigo «Current Challenges for African Cultural Heritage: A Case Study of Guinea-Bissau» da investigadora portuguesa Ana Temudo. $\mathrm{O}$ artigo coloca a tónica num tema quente da museologia contemporânea, a descolonização, que tem sido apontada como uma das grandes tendências globais a influenciar de forma crescente a actuação dos museus (Fleming 2019; Center for the Future of Museums 2019). Este é um tema que pode assumir contornos políticos e legais, mas é também uma questão deontológica e filosófica, implicando uma maior abertura para reflectir sobre as práticas do museu, revendo o passado e repensando formas de trabalhar. A restituição de bens culturais é um aspecto central desta discussão, que evoca a necessidade de investimento na pesquisa de procedência de objectos e o reconhecimento de que as coleções foram sendo reunidas durante longos períodos de tempo, de várias formas e a partir de uma grande diversidade de contextos. Temudo contextualiza a discussão sobre a restituição de bens culturais no campo internacional, 
situando o tema em Portugal - a forma como tem sido enquadrado no campo legislativo e nas instituições do património, e o debate emergente na esfera pública dos últimos anos. À luz destas discussões, a autora discute ainda a realidade museológica da GuinéBissau, antiga colónia portuguesa, através da história do seu Museu Etnográfico Nacional.

18 A fechar a secção de artigos, o enfoque dirige-se para uma análise da realidade britânica, com o texto «O Impacto das Políticas Culturais no Desenvolvimento de Programas para Jovens na Tate (1989-2019)» da autoria da investigadora Carolina Silva. A autora examina a influência das políticas culturais e subsequentes apoios à criação de programas educativos, nomeadamente os destinados a jovens, no contexto da Tate Britain, da Tate Modern, da Tate Liverpool e da Tate St Ives, ao longo de 30 anos. As conclusões reconhecem uma influência concreta das políticas culturais no alavancar da programação do museu para estes públicos, mas reconhece que a sustentabilidade destes programas reside também num compromisso mais continuado e integrado na missão do museu.

A contemporaneidade traz novos cenários e realça tendências, entre estas, abordagens mais centradas no paradigma da democracia cultural e o contributo de novas reconceptualizações da "participação" como mecanismo facilitador da construção de novas formas de envolvimento e a partilha de responsabilidades. É precisamente acerca destas abordagens que trata o ensaio de Sara Barriga Brighenti, que se intitula «A Cultura e a Promoção da Democracia: Recomendações da Carta do Porto Santo para os Museus». O ensaio tem como referencial a Carta do Porto Santo (2021), um documento promovido pelo Plano Nacional das Artes (Ministério da Cultura e Ministério da Educação de Portugal), que contém 37 recomendações com vista à implementação da democracia cultural. A partir deste enquadramento, Brighenti propõe uma reflexão sobre as implicações do modelo de democracia cultural para os museus.

A última secção deste dossier inclui um conjunto de seis recensões críticas de livros. Destaca-se no campo internacional a publicação Cultural Policies in Europe: A Participatory Turn (ed. Félix Dupin-Meynard e Emmanuel Négrier), recenseada por Flora Maravalhas. Aborda o papel da participação nas políticas públicas, a partir de diferentes perspetivas teóricas e históricas, proporcionando vários exemplos de práticas participativas da área da cultura em diferentes espaços geográficos europeus. Embora o foco não seja especificamente o dos museus, o livro permite várias leituras sobre o tema da participação no âmbito das políticas culturais. $O$ artigo de Lluís Bonet e Mariano Martín-Zamorano merece uma referência, pela distinção entre contexto cultural, modelo de governança e estratégias culturais, e pela discussão das diferenças entre participação cidadã, desenvolvimento de públicos e estratégias de participação cultural nos contextos das democracias liberais e iliberais.

Museum Activism (ed. Robert R. Janes e Richard Sandell) é o segundo título de circulação internacional da secção de recensões críticas. Comentado por Laura Castro, o livro defende a ideia de maior activismo por parte dos museus face a temas que desafiam a sociedade contemporânea, como sejam as migrações, a descolonização, o feminismo, as alterações climáticas, a inclusão, a justiça social, os direitos humanos, entre outros. Até certo ponto, parece reforçar a ideia do softpower dos museus (Lord e Blankenberg 2015), ou seja, a possibilidade de activar a capacidade dos museus em influenciar comportamentos e estabelecer agendas. O livro alicerça-se na prática, reflectindo em 
torno de vários casos de estudo que evidenciam um leque de possibilidades e caminhos em que esta prática activista se pode concretizar.

Ainda no campo das edições internacionais e na senda da expansão do papel social dos museus, o livro Socializing Art Museums: Rethinking the Publics' Experience (ed. Alejandra Alonso Tak e Ángel Pazos-López, recenseado por Sofia Carvalho, dá conta de tendências e práticas museológicas actuais comprometidas com a acessibilidade e a inclusão.

As últimas recensões da secção referem-se a três títulos da colecção portuguesa "Estudos de Museus" (ed. Direção-Geral do Património Cultural e Caleidoscópio), que visa a publicação de teses de doutoramento. Neste contexto, inclui-se a recensão de André de Soure Dores sobre o livro O Palácio Nacional da Ajuda e a sua Afirmação como Museu, da autoria de Luís Soares, que se debruça sobre a história e musealização do Palácio entre 1910 e 1981; a recensão de José Gabriel Andrade acerca do livro Realidade Aumentada em Exposições de Museu. Experiências dos Utilizadores, de Diana Marques, que se situa no campo da aplicação das tecnologias em contexto de museu; e uma última recensão, de Miguel Ferrão, sobre o livro da autoria de Sofia Ponte, Transformar Arte Funcional em Objeto Museal, que estuda as exposições de obras tidas como "arte funcional" em museus de arte.

Prestamos um agradecimento especial à artista e pesquisadora brasileira Aline Dias, que nos cedeu uma imagem para a capa deste número. A escolha de obras de artistas para as capas da MIDAS visa o prolongamento da discussão sobre museus, sobre os seus modos de existência e sobre como são percebidos ou vividos na contemporaneidade sob o olhar dos artistas contemporâneos. Assim, a capa do 13. número da MIDAS tem por base uma imagem pertencente a uma série de fotografias que Aline Dias realizou entre 2012 e 2015, intitulada "Lição de casa: museus". Nesta série, as fotografias são criadas a partir do interior de museus, mas focando o seu entorno. No caso da imagem escolhida para a capa da MIDAS, a fotografia foi criada a partir do interior do Museu Nacional de Machado de Castro, em Coimbra, observando a sua área envolvente. Sobre esta série de fotografias, feitas a partir de janelas e frestas do interior de museus, Aline Dias, comenta: «Comportando detalhes banais, a série empreende a tarefa de pensar o fora do museu, em seu sentido literal e também em franca e produtiva disparidade com as imagens visadas pelos discursos e práticas artísticas e institucionais». Neste contexto, agradecemos igualmente à Elisa Noronha Nascimento pela curadoria da capa e pelo arranjo gráfico final.

Destinamos as palavras finais deste editorial às autoras e aos autores, agradecendo as suas propostas de artigos, aos referees pela disponibilidade e colaboração, e à Sofia Carvalho - que recentemente se juntou à MIDAS, pelo apoio na revisão editorial.

\section{BIBLIOGRAFIA}

"Carta do Porto Santo. A Cultura e a Promoção da Democracia: Para uma Cidadania Cultural Europeia." 2021. https://portosantocharter.eu/wp-content/uploads/2021/05/

CartaDoPortoSanto.pdf 
Anico, Marta. 2009. "Políticas da Cultura em Portugal e Espanha." PASOS. Revista de Turismo y Patrimonio Cultural 7 (1): 57-71.

Arts Council England. 2019. Let's Create: Strategy 2020-2030. [Londres]: Arts Council England.

Bonet, Lluis, e Emmanuel Négrier. 2011. "The End(s) of National Cultures? Cultural Policy in the Face of Diversity." International Journal of Cultural Policy 17 (5): 574-89.

Camacho, Clara Frayão, ed. 2021. Grupo de Projeto Museus no Futuro: Relatório Final. Lisboa: DireçãoGeral do Património Cultural. Lisboa. http://patrimoniocultural.gov.pt/static/data/docs/ 2021/02/15/RelatorioMuseusnoFuturo.pdf.

Camacho, Clara Frayão. 2015. Redes de Museus e Credenciação: Uma Panorâmica Europeia. Vol. 2. Coleção Estudos de Museus. Casal de Cambra: Caleidoscópio e Direção-Geral do Património Cultural.

Carvalho, Ana, coord. 2017. "Lei-Quadro dos Museus Portugueses: Balanço e Perspectivas." Boletim ICOM Portugal, série III, n.․ 10 (out.). http://hdl.handle.net/10174/21432

Carvalho, Ana, e Roberto Falanga. 2016. "Da Democratização das Formas de Governação na Política à Partilha de Autoridade no Campo dos Museus e do Património.” In Participação: Partilhando a Responsabilidade, ed. Ana Carvalho, 29-44. Lisboa: Acesso Cultura. http:// hdl.handle.net/10174/18658

Center for the Future of Museums. 2019. TrendsWatch 2019: Executive Summary. [s.1.]: American Alliance of Museums.

Eidelman, Jacqueline, ed. 2017. Rapport de la Mission Musées do XXIe Siècle. Vol. I. [Paris]: Ministère de la Culture et de la Communication, Direction Générale des Patrimoines.

Eilertsen, Lill, e Bugge Amundsen Arne, eds. 2012. Museum Policies in Europe 1990 - 2010: Negotiating Professional and Political Utopia. Linköping: Linköping University Electronic Press.

Fleming, David. 2019. “Global Trends in Museums.” Museum International 71 (1-2): 108-13.

Garcia, José Luís, João Teixeira Lopes, Teresa Duarte Martinho, José Soares Neves, Rui Telmo Gomes, e Vera Borges. 2016. "Mapping Cultural Policy in Portugal: From Incentives to Crisis." International Journal of Cultural Policy 24 (5): 577-93.

Gilabert González, Luz María. 2011. “La Gestión de Museos: Análisis de las Políticas Museísticas en la Peninsula Ibérica.” Tese de Doutoramento, Universidad de Murcia.

Höglund, Maria. 2012. “European Union Approaches to Museums 1993-2010.” In Museum Policies in Europe 1990 - 2010: Negotiating Professional and Political Utopia, editado por Lill Eilertsen e Bugge Amundsen Arne, 157-88. Linköping: Linköping University Electronic Press.

Hushion, Nancy, 2006a. "Editorial" [Museums and Cultural Policy]. Museum International Vol. LVIII (4/232): 4-7.

Hushion, Nancy, ed. 2006b. "Museums and Cultural Policy." Museum International Vol. LVIII (4/232).

Ibermuseus. 2020. o que os Museus Necessitam em Tempos de Distanciamento Físico. [s.l.]: Ibermuseus. http://www.ibermuseos.org/wp-content/uploads/2020/07/informecovid-vf.pdf

Ibermuseus. 2021. Profissionais de Museus Ibero-americanos diante do Covid-19. [s.1.]: Ibermuseus. http://www.ibermuseos.org/wp-content/uploads/2021/04/profesionales-de-museos-y-covid-19oimibermuseoses-pt.pdf 
ICOM. 2020. Follow-up Survey: The Impact of COVID-19 on the Museum Sector. Paris: ICOM (International Council of Museums). https://icom.museum/wp-content/uploads/2020/11/FINALEN_Follow-up-survey.pdf

Lang, Caroline, John Reeve, e Vicky Woollard. 2006. "The Impact of Government Policy.” In The Responsive Museum: Working with Audiences in the Twenty-first Century, 19-28. Hampshire: Ashgate e Burlington.

Legget, Jane, ed. 2017b. “Museums and Public Policy.” Museum International 69 (275-276).

Legget, Jane. 2017a. "Museums and Public Policy: An Introduction." Museum International 69 (275276): 6-9.

Lopes, João Teixeira. 2009. "Da Democratização da Cultura a um Conceito e Prática Alternativos de Democracia Cultural.” Saber \& Educar, n.․ 14: 1-13.

Lord, Gail Dexter, e Ngaire Blankenberg, eds. 2015. Cities, Museums and Soft Power. Washington, D.C: The AAM Press.

Mattila, Mirva, ed. 2018. Museum of Opportunities: The Museum Policy Programme 2030 of the Ministry of Education and Culture. [Helsínquia]: Ministry of Education and Culture, Finland.

Négrier, Emmanuel. 2020. “Introduction.” In Cultural Policies in Europe: a Participatory Turn?, ed. Félix Dupin-Meynard e Emmanuel Négrier, 11-27. Toulouse: Éditions de l’Attribut.

NEMO. 2021. Follow-up Survey on the Impact of the COVID-19 Pandemic on Museums in Europe - Final Report. [n.p.]: NEMO (Network of European Museum Organizations). https://www.ne-mo.org/ fileadmin/Dateien/public/NEMO_documents/NEMO_COVID19_FollowUpReport_11.1.2021.pdf Norwegian Ministry of Culture, eds. 2019. The Power of Culture. Culture Policy for the Future. Meld. St. 8 (2018-2019). Report to the Storting (white paper) Summary. [Oslo]: Norwegian Ministry of Culture.

Poirrier, Philippe, ed. 2011. Pour une Histoire des Politiques Culturelles dans le Monde. Paris: La Documentation Française.

Poulot, Dominique, dir. 2016. "Le Musée et le Politique.” Culture \& Musées (28). https:// journals.openedition.org/culturemusees/783

UNESCO. 2020. Museums Around the World in the Face of COVID-19. https://unesdoc.unesco.org/ark:/ 48223/pf0000373530

Vale, Paulo Pires do. 2021. “Territorializar, Mobilizar e Indisciplinar: Estratégias do Plano Nacional das Artes - Entrevista a Paulo Pires do Vale, por Ana Carvalho." In Museus e Responsabilidade Social - Participação, Redes e Parcerias (23-24 Março 2021). Direção-Geral do Património Cultural (DGPC). https://nomundodosmuseus.hypotheses.org/9336

\section{NOTAS}

1. As autoras escrevem de acordo com a antiga ortografia. 


\section{AUTORES}

\section{ANA CARVALHO}

Investigadora contratada no Centro Interdisciplinar de História, Culturas e Sociedades (CIDEHUS) da Universidade de Évora. Lecciona na área da museologia e do património na mesma Universidade. Entre 2015 e 2021, fez o pós-douramento no CIDEHUS com uma bolsa da Fundação para a Ciência e a Tecnologia (FCT). Doutoramento e mestrado em Museologia. Membro do Grupo de Projecto Museus no Futuro (2019-2020), uma iniciativa do Ministério da Cultura, com o objectivo de propor recomendações de política pública para o sector dos museus e do património. Colaborou como investigadora no projecto Mu.SA - Museum Sector Alliance (2016-2020). Coordenou o Boletim do ICOM Portugal (2014-2018). A sua investigação tem-se centrado em temas do património e da museologia contemporânea.

CIDEHUS - Centro Interdisciplinar de História, Culturas e Sociedades da Universidade de Évora, Palácio do Vimioso, Largo do Marquês de Marialva, n.o 8, Apartado 94, 7000-809 Évora, Portugal, arcarvalho@uevora.pt

\section{CLARA FRAYÃO CAMACHO}

Museóloga da Direção-Geral do Património Cultural e colaboradora do Plano Nacional das Artes. Investigadora do Instituto de História de Arte (Faculdade de Ciências Sociais e Humanas - FCSH, Universidade Nova - NOVA). Doutorada em História (Universidade de Évora) e mestre em Museologia e Património (FCSH - NOVA). Dirigiu o Museu Municipal de Vila Franca de Xira, foi coordenadora da Rede Portuguesa de Museus, subdiretora do Instituto Português de Museus/ Instituto dos Museus e da Conservação e coordenadora do Grupo de Projecto Museus no Futuro na dependência da Ministra da Cultura. Docente de disciplinas de museologia em várias universidades e autora de artigos sobre temas de museologia contemporânea, redes e credenciação. Participa em grupos de trabalho internacionais e de representação institucional em organismos europeus e ibero-americanos.

Plano Nacional das Artes, Campo Grande, n. 83, 1.ำ 1700-088 Lisboa, Portugal, claracamacho@dgpc.pt

\section{RAQUEL HENRIQUES DA SILVA}

Professora catedrática na Faculdade de Ciências Sociais e Humanas da Universidade Nova de Lisboa, Departamento de História da Arte de que é coordenadora executiva desde 2015. Lecciona seminários do mestrado em História da Arte do século XIX e do mestrado em Museologia; é coordenadora do curso de doutoramento em História da Arte. Autora de estudos de investigação e divulgação nas áreas do urbanismo e arquitetura (século XIX-XX), artes plásticas e museologia. Comissária de exposições de arte. Foi directora do Museu do Chiado (1994-1997) e do Instituto Português de Museus (1997-2002). Integrou o Conselho de Administração da Fundação de Serralves (2000-2006) e, actualmente, integra o Conselho de Administração da Fundação ArpadSzenes-Vieira da Silva. É directora científica do Museu do Neo-Realismo desde 2018. Instituto de História da Arte, Faculdade de Ciências Sociais e Humanas, Universidade de Lisboa, Colégio Almada Negreiros, Campus de Campolide, 1070-312 Lisboa, Portugal, raquelhs10@gmail.com 